\title{
Globally Distributed Drug Discovery of New Antibiotics: Design and Combinatorial Synthesis of Amino Acid Derivatives in the Organic Chemistry Laboratory
}

Amy B. Dounay, ${ }^{\text {a }}$ Martin J. O’Donnell, ${ }^{\mathrm{b}}$ J. Geno Samaritoni, ${ }^{\mathrm{b}}$ Lukasz Popiolek, ${ }^{\mathrm{c}}$ Douglas Schirch, ${ }^{\mathrm{d}}$ Anna Biernasiuk, ${ }^{e}$ Anna Malme Isaac W. Lamb, ${ }^{b}$ Kristen Mudrack, ${ }^{\mathrm{f}}$ Daniel G. Rivera,g Gerardo M. Ojeda, $\mathrm{g}$ William L. Scottb

aDepartment of Chemistry and Biochemistry, Colorado College, 14 E. Cache La Poudre Street, Colorado Springs, CO 80919

b Department of Chemistry and Chemical Biology, Indiana University-Purdue University Indianapolis, 402 N. Blackford St. Indianapolis, IN 46202

c Department of Organic Chemistry, Medical University of Lublin, Lublin, Poland, Address: Chodzki 4A Street, 20-093 Lublin, Poland

d Department of Chemistry, Goshen College, 1700 South Main Street, Goshen, Indiana 46526

eDepartment of Pharmaceutical Microbiology, Medical University of Lublin, Lublin, Poland, Address: Chodzki 1 Street, 20-093 Lublin, Poland

f Department of Chemistry, Milligan College, 1 Blowers Boulevard, Milligan College, TN 37682

g Center for Natural Products Research, Faculty of Chemistry, University of Havana, Zapata y G, 10400, La Habana, Cuba

\begin{abstract}
An experiment for the synthesis of $N$-acyl derivatives of natural amino acids has been developed as part of the Distributed Drug Discovery (D3) program. Students use solid-phase synthesis techniques to complete a three-step, combinatorial synthesis of six products, which are analyzed using LC-MS and NMR spectroscopy. This protocol is suitable for introductory organic laboratory students and has been successfully implemented at multiple academic sites internationally. Accompanying pre-lab activities introduce students to SciFinder and to medicinal chemistry design principles. Pairing of these activities with the laboratory work provides students an authentic and cohesive research project experience.
\end{abstract}

This is the author's manuscript of the article published in final edited form as:

Dounay, A. B., O’Donnell, M. J., Samaritoni, J. G., Popiolek, L., Schirch, D., Biernasiuk, A., ... Scott, W. L. (2019). Globally Distributed Drug Discovery of New Antibiotics: Design and Combinatorial Synthesis of Amino Acid Derivatives in the Organic Chemistry Laboratory. Journal of Chemical Education, 96(8), 1731-1737. https://doi.org/10.1021/acs.jchemed.8b00942 


\section{Combinatorial synthesis of representative $3 \times 2$ array}

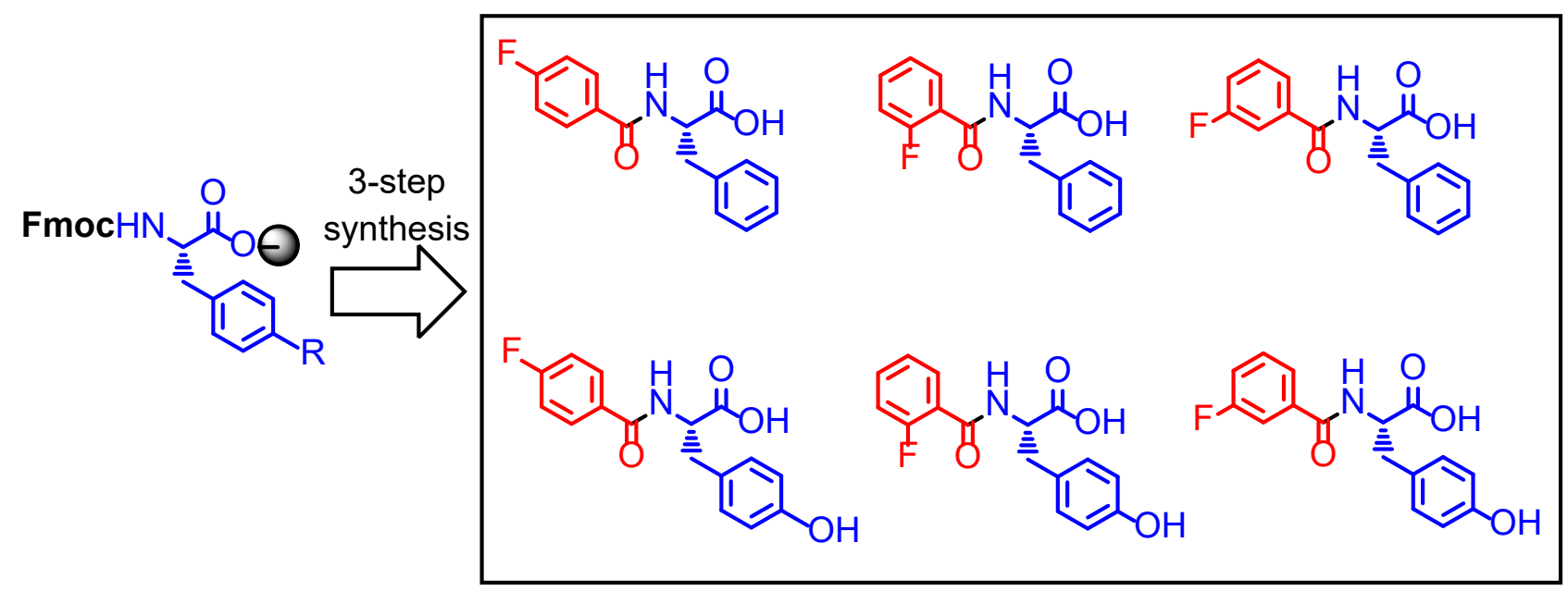

\section{KEYWORDS}

Laboratory Instruction, Hands-on Learning/Manipulatives, Second-Year Undergraduate, Amino Acids, Medicinal Chemistry, Synthesis

\section{INTRODUCTION}

Numerous studies have highlighted the benefits of guided-inquiry and research project-based experiments in undergraduate chemistry laboratory courses. ${ }^{1-8}$ The Distributed Drug Discovery (D3) program $^{9-13}$ is one of several initiatives that introduces organic chemistry students to drug discovery and combinatorial synthesis through course-based research projects. ${ }^{14-17}$ By integrating targeted syntheses of bioactive molecules into teaching laboratories, the D3 program seeks to combine undergraduate chemistry education with broader research efforts in drug discovery. It also offers students hands-on experience with solid-phase synthesis, ${ }^{18-23}$ complementing the solution-phase techniques typically taught in undergraduate laboratory courses. ${ }^{24}$ D3 chemistry protocols are designed to be robust, reproducible, and accessible to undergraduates in a variety of academic environments worldwide. The first reported D3 protocol (D3 Lab 1) involved the $\alpha$-alkylation of glycine derivatives for the preparation of unnatural amino acid derivatives using a five-step synthesis. ${ }^{12}$

In the new D3 laboratory experiment (D3 Lab 2) described herein, students complete a threestep synthesis to prepare $N$-acyl derivatives of natural amino acids (Scheme 1). Compounds in this class have demonstrated antibiotic activity and therefore represent a useful starting point for further 
optimization. ${ }^{25-28}$ In contrast to the five-step D3 Lab 1 protocol, ${ }^{12}$ this shorter D3 Lab 2 experiment is suitable to a wider range of laboratory environments. Another unique new feature of this D3 experiment is the involvement of students in both the design and synthesis of new compounds for drug discovery programs; few other initiatives engage undergraduate students in drug design. ${ }^{16,29-32}$ This experiment includes the following three components, including two previously unreported pre-lab activities:

1) Pre-lab SciFinder exercise

2) Pre-lab medicinal chemistry design activity

3) Experimental work and post-lab analysis

The first two components introduce students to SciFinder tools and drug design principles prior to initiation of the laboratory work, enhancing the authenticity of the research experience. In the third component, students use a combinatorial "Bill-Board" array design (Figure 1) using two Fmoc-protected amino acids (Step 1) and three substituted benzoic acids (Step 2) to prepare a six-compound array of $N$ acylamino acids (Figure 2), which are analyzed using LC-MS and NMR spectroscopy. The final products from this synthesis are suitable for submission to biological assays, such as the Community for Open Antimicrobial Drug Discovery (Co-ADD) screening panel.33,34 The modular design of these activities allows instructors to implement any or all of the components to fit their schedules and resources. A complete set of classroom materials and protocols are provided to enable chemistry students and faculty from a diversity of settings to participate in the D3 synthesis program. 
Scheme 1. D3 Lab 2: Solid-Phase Synthesis of $N$-Acylated Natural $\alpha$-Amino Acids ${ }^{a}$

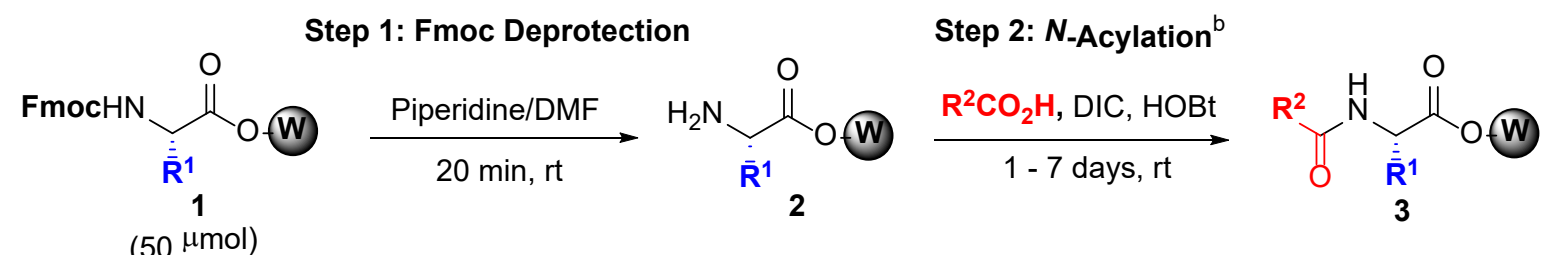

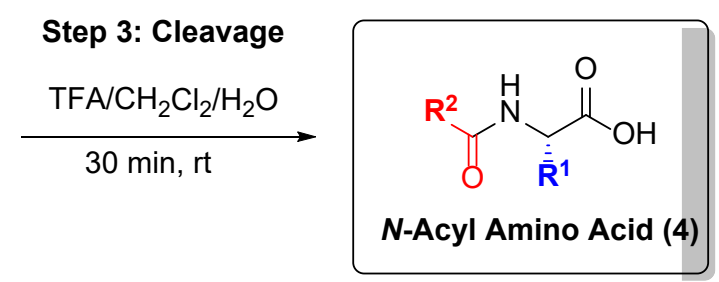

$\mathrm{a} \mathrm{W}=$ Wang resin $; \mathrm{DMF}=N, N$-dimethylformamide; $\mathrm{DIC}=$ diisopropylcarbodiimide $; \mathrm{HOBt}=1$-hydroxybenzotriazole; $\mathrm{TFA}=$ trifluoroacetic acid; bReaction times variable due to instructional lab scheduling differences across institutions; reaction outcomes are not noticeably affected by variation of reaction time within this range.

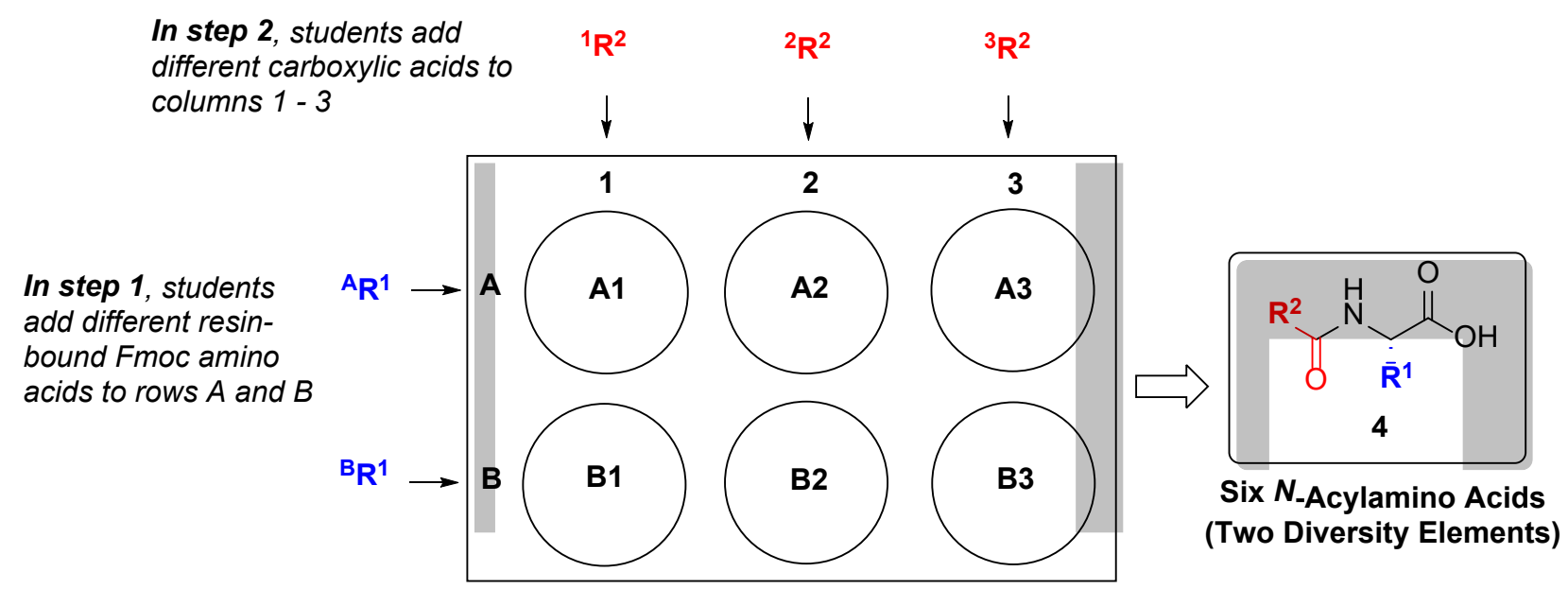

Figure 1. Bill-Board array depicting combinatorial array for diversity steps in synthesis of 4. 


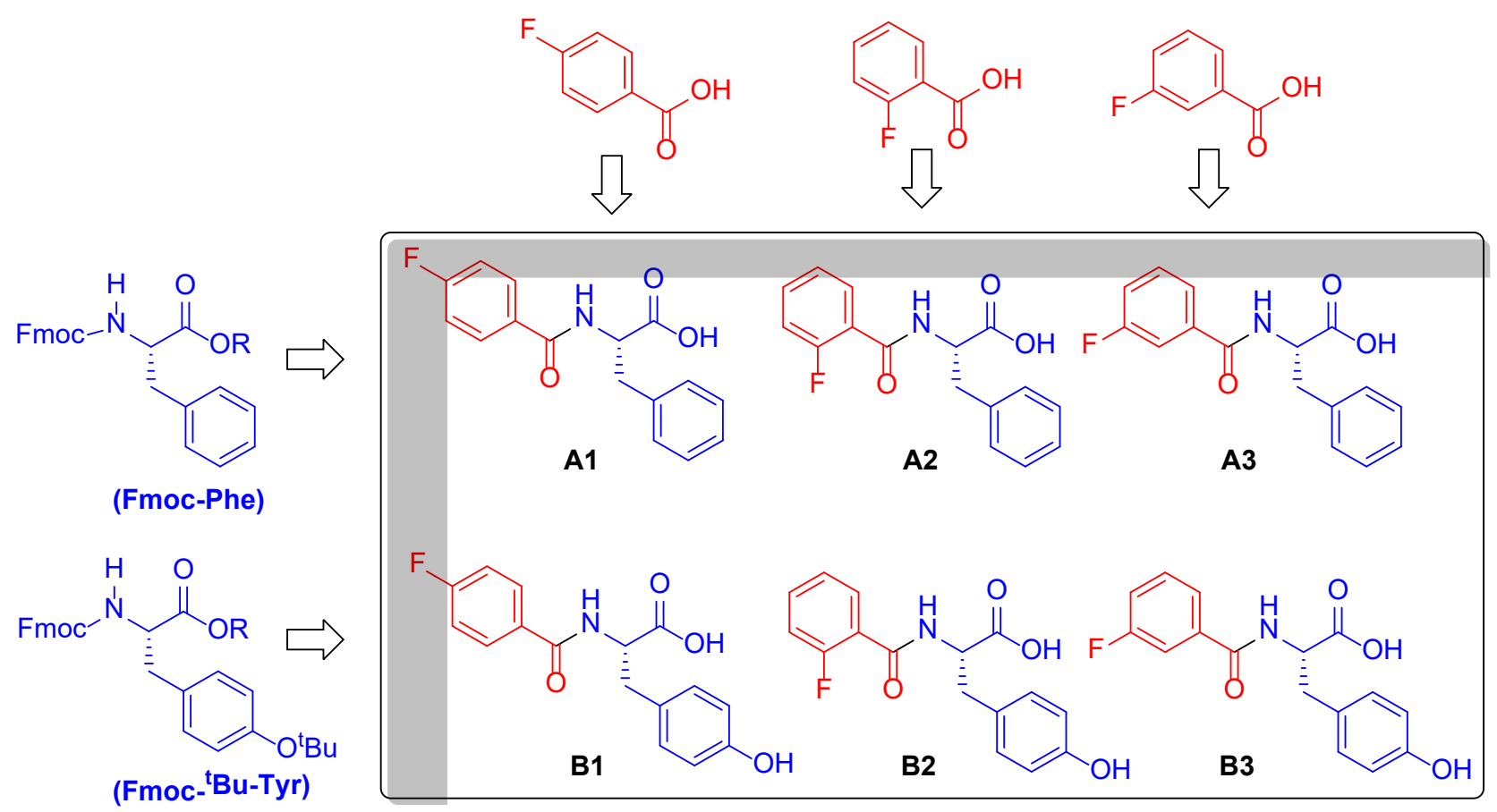

Figure 2. Representative array illustrating combinatorial products from two diversity elements

\section{OVERVIEW: DESIGN AND SYNTHESIS}

Students may work individually or in pairs and can complete the laboratory component of the experiment over four $3-4 \mathrm{~h}$ lab periods (Table 1). A prelab meeting and prelab videos are typically used to introduce the overall program and specific reactions. ${ }^{35}$ The laboratory component can be supplemented by two additional pre-lab activities, described below. 


\section{Table 1. Timeline for Classroom Activities and Laboratory Tasksa}

\begin{tabular}{|c|c|}
\hline $\begin{array}{c}\text { Laboratory or } \\
\text { Classroom Sessior }\end{array}$ & Activities /Tasks ${ }^{b}$ \\
\hline 1 & $\begin{array}{l}\text { Pre-Lab Lecture: Introduction to drug discovery and D3 } \\
\text { program, solid-phase combinatorial synthesis, and } \\
\text { SciFinder } \\
\text { - Pre-Lab Classroom Activity or Homework: Students } \\
\text { complete SciFinder worksheet/exercise }\end{array}$ \\
\hline 2 & - Pre-Lab Classroom Activity: D3 Bill-Board Design Activity \\
\hline 3 & $\begin{array}{l}\text { Laboratory Session 1: Students prepare reagent solutions } \\
\text { and complete reactions } 1 \text { and start reaction } 2 \text { (Fmoc } \\
\text { deprotection and } N \text {-Acylation) }\end{array}$ \\
\hline 4 & $\begin{array}{l}\text { Laboratory Session 2: Students work-up reaction 2, } \\
\text { complete reaction } 3 \text { (cleavage of product from resin) and } \\
\text { prepare samples for LC-MS; students observe LC-MS } \\
\text { instrument demonstration }\end{array}$ \\
\hline 5 & $\begin{array}{l}\text { - Laboratory Session 3: Students weigh crude products and } \\
\text { analyze by TLC; each student purifies one product by } \\
\text { column chromatography and submits purified sample for } \\
\text { LC-MS }\end{array}$ \\
\hline 6 & $\begin{array}{l}\text { - Laboratory Session 4: Students obtain }{ }^{1} \mathrm{H} \text { NMR data on } \\
\text { purified product, store/submit samples }\end{array}$ \\
\hline 7 & $\begin{array}{l}\text { Post-Lab Classroom Activity: Discussion of LC-MS and } \\
\text { NMR data sets, reaction outcomes, and final report } \\
\text { expectations }\end{array}$ \\
\hline $\begin{array}{l}\text { a Schedule represe } \\
\text { undergraduate org } \\
\text { schedules used at } \\
\text { SI-2 pp 2-3.bLabor } \\
\text { sessions; Laborato }\end{array}$ & $\begin{array}{l}\text { le for D3 experiment in second-semester introductory } \\
\text { istry course at Colorado College, Spring 2018; Alternative } \\
\text { University of Havana are provided in the Supporting Information } \\
\text { re or classroom activities are completed in } 60-90 \text { min class } \\
\text { are completed in 3-4 h. }\end{array}$ \\
\hline
\end{tabular}

\section{SciFinder Search Activity}

Development of information literacy is an important pedagogical goal for undergraduate chemistry curricula. ${ }^{36-38}$ The learning objective of the new SciFinder component of this D3 program is for students to learn to use SciFinder to obtain key data and vendor information prior to beginning a new research project. The worksheet activity (Supporting Information, (SI)-1, pp 3-6) can be completed in class ( 60 - $90 \mathrm{~min}$ ) or as a homework assignment after a general introduction to SciFinder. Students completing this exercise gain information literacy, including proficiency using the structure searching capabilities 
of SciFinder and finding commercial availability, pricing, and NMR spectral data for chemicals relevant to their D3 experiment.

\section{Bill-Board Design Activity}

The pedagogic goal of this pre-lab activity is for students to learn to utilize structure-activity relationship (SAR) data to practice hypothesis-driven drug design. Earlier versions of the D3 experiments assigned each student a specific six-compound array (e.g., Figure 2) designed by the instructor. Involving students in the design of their own Bill-Board arrays underscores their participation as collaborators in the research process. This activity, which includes a worksheet (SI-1, pp 7-13) and instructor-led discussion, can be completed in a $60-90$ min class session. In the first part of the activity, students work in pairs to evaluate a set of antimicrobial data for a set of $N$-acylamino acids accessible by D3 Lab 2. ${ }^{39}$ The instructor may prompt students to consider features that may contribute to drug-protein binding interactions, including electron-withdrawing groups (e.g., nitro- or fluoroaryl groups) that may impact electrostatic interactions or functional groups that participate in hydrogen bonding (e.g., tyrosine vs. phenylalanine). Students may also consider the strategic benefits of evaluating derivatives of closely related amino acids (e.g., tyrosine and phenylalanine) versus a structurally diverse compound set (e.g., phenylalanine vs. isoleucine). Using the provided data, students develop SAR hypotheses and propose their set of new analogs to synthesize in the lab. The instructor can emphasize that there is no "right" answer in this exercise. Rather, students may choose different SAR questions to interrogate via their selected Bill-Board designs.

To ensure Bill-Board replication within each laboratory section, the class is then typically divided into three to four "medicinal chemistry" teams, with six to ten students per team. ${ }^{40}$ In this second phase of the activity each team works to design one Bill-Board that all students in that team will synthesize (i.e., students work in pairs on a Bill-Board in the laboratory, allowing the selected Bill-Board array to be synthesized in replicate at least three times). During this activity, students explain and defend their hypotheses to their peers and negotiate toward a final team proposal. Students become highly engaged in this exercise, which is intended to simulate a real-world situation in which chemists prioritize ideas and agree upon synthetic targets. In an instructor-led discussion, each team then presents their proposals to the class. If multiple teams have proposed the same Bill-Board design, the instructor may 
suggest changes to ensure sufficient chemical diversity across the class set of Bill-Boards. Enabling students to contribute to the selection of their synthetic targets through this exercise ultimately increases student ownership and engagement in the project.

\section{Materials}

Students use the commercially available Bill-Board apparatus ${ }^{41}$ for the combinatorial solid-phase syntheses. Bill-Board equipment organizes six reactions and simplifies the repeated cycles of reactions and washings, product collection, and solvent evaporation. It includes three modular polypropylene components:

1) A reaction board fitted with six fritted glass reaction vessels arranged in a two by three grid

2) A channeled drain tray to facilitate collection of solvent and reagent washes into a waste beaker

3) A collection vial rack with six wells to hold $25 \times 52 \mathrm{~mm}$ vials

Laboratory Experiment and Post-Lab Analysis

The learning objectives (LOs) of the laboratory experiment are for students to:

1) Complete a three-step combinatorial synthesis using solid-phase synthesis techniques.

2) Purify a final product using column chromatography.

3) Obtain and analyze TLC, LC/MS, and ${ }^{1} \mathrm{H}$ NMR data for their final products to assess compound purity and identity.

4) Contribute to the D3 program by providing compounds for biological screening in antibiotic assays.

In the first laboratory session, students deprotect the Fmoc group from the resin-bound amino acids. Students wash the resins and add the necessary reagents for the $N$-acylation step. This reaction is completed overnight, but for courses meeting weekly, this step can proceed for a week. In the second laboratory session, students wash the resins to remove excess reagents and cleave the $N$-acylated products from the resin using trifluoroacetic acid. Students submit an aliquot of each crude product solution for LC-MC analysis. In the third lab session, students weigh their crude products and calculate crude yields. Students complete TLC analysis on all six crude product samples. Each student purifies one compound by column chromatography and obtains LC-MS data on the purified product. ${ }^{42}$ Finally, 
in a fourth laboratory session, students obtain ${ }^{1} \mathrm{H}$ NMR data on their purified samples prior to final sample submission.

\section{HAZARDS}

See the Supporting Information (SI-2, pp 6-8) for a complete list of reagents, CAS numbers, supplier information, and hazard statements. The product $N$-acylamino acids should be assumed to have biological activity, and direct contact should be avoided. Students and instructors should use standard laboratory safety precautions and should handle all solvents, reagents, and products in a fume hood while wearing standard personal protective equipment, including gloves, lab coats, and goggles.

\section{RESULTS AND DISCUSSION}

Students have reproducibly executed this experiment in diverse settings, including second-semester, introductory undergraduate organic chemistry laboratories at IUPUI; short format Block Plan courses at Colorado College; a four-day workshop at the University of Havana; ${ }^{43}$ and independent research labs at Goshen College and Medical University of Lublin (Table 2). In total, over 950 students have completed this laboratory experiment, and a diverse set of compounds has been prepared, with replication within and between participating institutions (SI-3).

Student learning in the prelab activities has been assessed using the student worksheets. By completing the SciFinder activity, all students $(n=32)$ in a second-semester introductory undergraduate organic chemistry course in 2018 at Colorado College demonstrated proficiency with this digital resource critical for practicing chemists, as shown by their scores on this worksheet (average score $=99 \pm 5 \%$ ). Students completed the Bill-Board design worksheet as part of an in-class activity, and these worksheets were not collected or graded. Students presented their hypotheses to the class as part of the activity, and the majority of students demonstrated the ability to use the available data to generate a reasonable hypothesis. The design activity also contributed to student motivation and engagement in the overall experimental process, as noted responses on student assessment of learning gains.

Recent data from two student groups completing this experiment in different settings (University of Havana, 2016 and Colorado College, 2018) demonstrated typical outcomes for laboratory groups 
against LO 1. The majority of students had little or no previous experience in multi-step, combinatorial, or solid-phase synthesis. At the University of Havana workshop, all students (100\%) successfully completed the combinatorial syntheses and achieved LO 1.44 Their crude A1 controls $(\mathrm{n}=10)$ had an average purity (LC-MS) of $82 \pm 11 \%$. Due to time constraints in this workshop format, students did not purify their compounds and LO 2 was not assessed in this group. In two recent laboratory sections at Colorado College, the targeted products were obtained in 14 out of 16 Bill-Boards. ${ }^{45}$ Thus, 28 out of 32 students (88\%) achieved LO 1.46 Within this Colorado College group, all students (100\%) were successful in purifying their products and achieving LO 2. The crude A1 products $(n=12)$ had an average purity of $56 \pm 10 \%$, which was improved to an average final purity of $91 \pm 6 \%$ after cyanosilica gel chromatography. An additional set of student samples $(n=20)$, which included greater structural diversity, had an average purity of $42 \pm 15 \%$ before purification and $84 \pm 11 \%$ after purification

\section{Table 2. Institutions involved in D3 Lab 2 Validation}

\begin{tabular}{|c|c|c|c|c|}
\hline Institution & Laboratory Format & $\begin{array}{l}\text { Total Lab } \\
\text { Sections }\end{array}$ & $\begin{array}{c}\text { Number of } \\
\text { Students } \\
\text { per } \\
\text { Section }\end{array}$ & $\begin{array}{c}\text { Total } \\
\text { Independent } \\
\text { Research } \\
\text { Students }\end{array}$ \\
\hline IUPUI & $\begin{array}{l}\text { One-semester, } \\
\text { undergraduate lab } \\
\text { course }\end{array}$ & 39 & 20 & 20 \\
\hline Colorado College & $\begin{array}{l}\text { Block Plan (short format) } \\
\text { undergraduate lab } \\
\text { course }\end{array}$ & 7 & $16-24$ & NA \\
\hline Goshen College & $\begin{array}{l}\text { Independent } \\
\text { undergraduate research } \\
\text { group }\end{array}$ & NA & NA & 17 \\
\hline University of Havana & $\begin{array}{l}\text { Four-day } \\
\text { undergraduate/ } \\
\text { graduate-level workshop }\end{array}$ & 1 & 24 & NA \\
\hline $\begin{array}{l}\text { Medical University of } \\
\text { Lublin }\end{array}$ & $\begin{array}{l}\text { Independent } \\
\text { undergraduate research } \\
\text { group }\end{array}$ & NA & NA & 8 \\
\hline
\end{tabular}

Most students participating in this laboratory experiment had no previous experience analyzing LC-MS data. Therefore, a post-lab classroom session in which the instructor helped guide students through an example LC-MS data set was essential for enabling students to achieve LO 3. Additionally, many students completing this experiment had not previously obtained ${ }^{1} \mathrm{H}$ NMR spectra of chiral compounds and had difficulty in correctly identifying the signals for the diastereotopic protons (e.g., 
benzylic signals in their phenylalanine or tyrosine derivatives). A brief instructor-led discussion on this aspect of ${ }^{1} \mathrm{H}$ NMR spectral characteristics may assist students in correctly assigning all signals in their ${ }^{1} \mathrm{H}$ NMR spectra. At Colorado College, student learning on LO 3 has typically been assessed using student laboratory reports (average lab report score $=94 \pm 3 \%$ ). .47 Most students $(>80 \%)$ are successful in analyzing and interpreting all of their data (TLC, LC-MS, and NMR) and correctly determining compound purity and identity (see SI-2 pp 20-23 for an example lab report grading rubric and student report). The most common student errors involved misassignment of signals in the ${ }^{1} \mathrm{H}$ NMR spectra. Independent undergraduate research students at Goshen College have demonstrated mastery of LO3 through completion of an advanced undergraduate thesis project report $(n=6$; average thesis report score $=92.2 \%$, range $91-94 \%$; grading rubric and sample thesis report included in SI-2, pp 24-58). At Colorado College and IUPUI, students also completed lab quizzes to assess pre-lab preparation and understanding of concepts and techniques (Example quizzes in SI-2 pp 17-19). In the recent Colorado College course, students demonstrated an acceptable level of pre-lab preparation and familiarity with the reaction protocols prior to the first laboratory session ( $\mathrm{n}=32$, Average score $78 \pm 16 \%$ ).

One key goal of this program (LO 4) is to provide compounds for biological screening for antibiotic drug discovery. Therefore, it is noteworthy that most students (typically $>80 \%$ ) in recent D3 labs produced a purified sample in sufficient quantity $(\geq 1-2 \mathrm{mg})$ and with appropriate purity (>85\%) for biological assays, such as bacterial growth inhibition assays. These biological assays are beyond the scope of organic chemistry instructional laboratories. Nevertheless, several collaborative approaches have been explored to involve undergraduate students in completing the full cycle of design, synthesis, and biological screening. For example, students in introductory microbiology courses and independent research laboratories at IUPUI have tested compounds from this experiment in a variety of simple assays. ${ }^{48-51}$ Independent research students at the Medical University of Lublin have also prepared and tested compounds from this experiment in antimicrobial assays and have identified active compounds. (Example assay protocols and data are included in the Supporting Information, SI-2 pp 61-64.) Synthetic products from this experiment have also been submitted to the CO-ADD screening panel.33,34 Student assessment of learning gains 
A Student Assessment of Learning Gains (SALG) instrument was completed by students at University of Havana and Colorado College. A common theme among students was their increased understanding of drug discovery and a sense of contribution to this enterprise. Examples of student responses are included in Table 3 (SALG instrument in SI-2 pp 59-60). Quantitative questions from the SALG survey also revealed topics and skills where students perceived the greatest learning gains after the D3 experiment (Table 3). All students noted gains in understanding how drugs are discovered and in their abilities analyze their data. Nearly all students (30/31) noted that doing experimental work helped their learning. These student-reported gains are consistent with other measures of success highlighted in the assessments described above. Numerous student comments indicated that the real-world applications of the D3 project were motivating and increased their engagement with the laboratory and classroom learning. Selected student comments include these observations:

- "I have learned a lot more about planning experiments to get meaningful results." [Colorado College student, 2018]

- "It made me feel like I was an integral part of the procedure of producing a new drug." [Colorado College student, 2018]

- "It has motivated me to take additional chemistry courses and expand my knowledge of solid phase synthesis." [University of Havana student, 2016]

- "This workshop showed me how chemistry can be very useful in helping humanity. It has motivated me to do research in the field of neglected disease." [University of Havana student, 2016]

- "Doing experimental work in groups mimics real world drug discovery." [Colorado College student, 2018] 
Table 3. Selected Survey Response Data from Students' Self-Reported Learning Gains

$\begin{array}{ll}\text { Statements for Response } & \text { Average Score, },^{a} N=31\end{array}$

As a result of your work on the D3 lab, what gains did you make in your understanding of the following?

How drugs are discovered 4.3

$4.3 \quad 0.8$

How the studies done in this lab address real-world issues

4.1

1.2

As a result of your work on the D3 lab, what gains did you make in the following skill?

Analyzing and interpreting experimental data

4.0

0.8

How much did each of the following aspects of the workshop help your learning?

Listening to workshop lectures

3.6

0.9

Working in groups

3.9

1.1

Doing experimental work

4.1

0.9

aScale has a range of $1-5$, with $1=$ no gains $/$ help; $2=$ a little gain $/$ help; $3=$ moderate gain $/$ help; $4=$ good gain/help; and 5 = great gain/help.

\section{CONCLUSIONS}

The complete set of design activities and laboratory experiments described herein represents the

culmination of years of multi-institutional efforts to realize the D3 chemistry vision: an accessible, undergraduate-focused and globally Distributed Drug Discovery program. Key components introduced students to the role of chemistry in drug discovery, involved them in the synthetic planning and design process, and enabled them to use well-described combinatorial solid-phase synthesis procedures and simple equipment to reproducibly synthesize new molecules as potential drug leads for antibiotic resistant infections. Through this experiment, students learned to complete the solid-phase synthesis, purification, and analysis of small organic molecules with potential bioactivity. Furthermore, students provided samples for screening in antibiotic assays and learn about an important humanitarian application of chemistry. The involvement of students from institutions in the U.S., Poland, and Cuba highlights the essential role of global collaboration in the research process. ${ }^{52-55}$ This experiment has been adapted to the variety of levels, resources, and educational goals represented by this diverse group of institutions.

The D3 program continues to expand its international collaborations and advance its mission by developing new synthesis procedures for additional classes of molecules, which can be enumerated into virtual catalogs for computational analysis and synthesis selection. ${ }^{56}$ As the D3 community expands, the program will gain from the unique experiences of students and instructors from diverse 
environments and will apply this learning in a powerful educational consortium searching for new antibiotic drugs.

\section{ASSOCIATED CONTENT}

Supporting Information

The Supporting Information is available on the ACS Publications website at DOI:

10.1021/acs.jchemed.XXXXXXX.

SI-1 Handouts for Students (PDF, DOCX)

SI-2 Information for Instructors (PDF, DOCX)

SI-3 Compounds Prepared Using D3-2 Laboratory Procedure (PDF, XLSX)

Link to Instructional Video: https://iu.box.com/s/4s7b30o5a984j5pvqj1nc3u4guecl2rt

\section{AUTHOR INFORMATION}

Corresponding Author

*E-mail: adounay@coloradocollege.edu

\section{ACKNOWLEDGMENTS}

This work was supported by funding from NSF/DUE-1140602 and the 2016 ACS Global Innovation

Grant. We are grateful to Amelia Fuller for assistance in editing this manuscript and to Tanya Cervantes,

Rachel Woncier, and ThanhTruc Pham for laboratory support.

\section{REFERENCES}

1. Gaddis, B. A.; Schoffstall, A. M. Incorporating Guided-Inquiry Learning into the Organic Chemistry Laboratory. J. Chem. Educ. 2007, 84 (5), 848 - 851.

2. Heemstra, J. M.; Waterman, R.; Antos, J. M.; Beuning, P. J.; Bur, S. K.; Columbus, L.; Feig, A. L.; Fuller, A. A.; Gillmore, J. G.; Leconte, A. M.; Londergan, C. H.; Pomerantz, W. C. K.; Prescher, J. A.; Stanley, L. M. Throwing Away the Cookbook: Implementing Course-Based Undergraduate Research Experiences (CUREs) in Chemistry. In Educational and Outreach Projects from the Cottrell Scholars Collaborative Undergraduate and Graduate Education Volume 1; ACS Symposium Series; American Chemical Society, 2017; Vol. 1248, pp 33-63.

3. Van Dyke, A. R.; Gatazka, D. H.; Hanania, M. M. Innovations in Undergraduate Chemical Biology Education. ACS Chem. Biol. 2018, 13 (1), 26-35.

4. Hunnes, C. H.; Dooley, D. M. Research Partnership between Teaching-Centered and ResearchIntensive Schools. J. Chem. Educ. 2004, 81 (7), 989-990.

5. Kowalski, J. R.; Hoops, G. C.; Johnson, R. J. Implementation of a Collaborative Series of Classroom-Based Undergraduate Research Experiences Spanning Chemical Biology, Biochemistry and Neurobiology. CBE Life Sci. Educ. [Online] 2016, 15 (4), Artilce ar55. 
6. Cookmeyer, D. L.; Winesett E. S.; Kokona, B.; Huff, A. R.; Sabina, A.; Bloch, N. B.; Bulos, J. A.; Evans, I. L;, Fagre, C. R.; Godbe, K. N.; Khromava, M.; Konstantinovsky, D. M.; Lafrance, A. E.; Lamacki, A. J.; Parry, R. C.; Quinn, J. M.; Thurston, A. M.; Tsai, K. J. S.; Mollo, A.; Cryle, M. J.; Fairman, R.; Charkoudian, L. K. Uncovering Protein-Protein Interactions through a TeamBased Undergraduate Biochemistry Course. PLoS Biol. [Online] 2017, 15 (11), Article e2003145.

7. Camacho, M. H.; Valcke, M.; Chiluiza, K. Research Based Learning in Higher Education: A Review of Literature. $11^{\text {th }}$ International Technology, Education and Development Conference. Chova, L. G.; Martinez A. L.; Torres, I. E., Eds. INTED Proceedings 2017, 4188-4197.

8. Haas, K. L; Hemmstra, J. M.; Medema, M. H.; Charkoudian, K. Collaborating with Undergraduates to Contribute to Biochemistry Community Resources. Biochemistry 2018, 57 (4), 383-389.

9. Scott, W. L.; O’Donnell, M. J. Distributed Drug Discovery, Part 1: Linking Academics and Combinatorial Chemistry to Find Drugs for Developing World Diseases. J. Comb. Chem. 2009, $11(1), 3-13$.

10. Scott, W. L.; Alsina, J.; Audu, C. O.; Babaev, E.; Cook, L.; Dage, J. L.; Goodwin, L. A.; Martynow, J. G.; Matosiuk, D.; Royo, M.; Smith, J.G.; Strong, A. T.; Wickizer, K.; Woerly, E. M.; Zhou, Z.; O’Donnell, M. J. Distributed Drug Discovery, Part 2: Global Rehearsal of Alkylating Agents for the Synthesis of Resin-Bound Unnatural Amino Acids and Virtual D3 Catalog Construction. J. Comb. Chem. 2009, 11 (1), 14-33.

11. Scott, W. L.; Audu, C. O.; Dage, J. L.; Goodwin, L. A.; Martynow, J. G.; Platt, L. K.; Smith, J. G.; Strong, A. T.; Wickizer, K.; Woerly, E. M.; O’Donnell, M. J. Distributed Drug Discovery, Part 3: Using $\mathrm{D}^{3}$ Methodology to Synthesize Analogs of an Anti-Melanoma Compound. J. Comb. Chem. 2009, 11 (1), 34-43.

12. Scott, W. L.; Denton, R. E.; Marrs, K. A.; Durrant, J. D.; Samaritoni, J. G.; Abraham, M. M.; Brown, S. P.; Carnahan, J. M.; Fischer, L. G.; Glos, C. E.; Sempsrott, P. J.; O’Donnell, M. J. Distributed Drug Discovery: Advancing Chemical Education through Contextualized Combinatorial Solid-Phase Organic Laboratories. J. Chem. Educ. 2015, 92 (5), 819 - 826.

13. Fuller, A. A. Combinatorial Solid-Phase Synthesis of Aromatic Oligamides: A Research-Based Laboratory Module for Undergraduate Organic Chemistry. J. Chem. Educ. 2016, 93 (5), 953 957.

14. Wolkenberg, S. E.; Su, A. I. Combinatorial Synthesis and Discovery of an Antibiotic Compound. J. Chem. Educ. 2001, 78 (6), $784-785$.

15. Whitaker, R. D.; Truhlar, L. M.; Yuksel, D.; Walt, D. R.; Williams, M. D. Synthesis and Biological Testing of Penicillins: An Investigative Approach to the Undergraduate Teaching Laboratory. J. Chem. Educ. 2010, 87 (6), 634 - 636. 
16. Fray, M. J.; Macdonald, S. J. F.; Baldwin, I. R.; Barton, N.; Brown, J.; Campbell, I. B.; Churcher, I.; Coe, D. M.; Cooper, A. W. J.; Craven, A. P.; Fisher, G.; Inglis, G. G. A.; Kelly, H. A.; Liddle, J.; Maxwell, A. C.; Patel, V. K.; Swanson, S.; Wellaway, N. A Practical Drug Discovery Project at the Undergraduate Level. Drug Disc. Today. 2013, 18 (23, 24), 1158-1172.

17. Streu, C. N.; Reif, R. D.; Neiles, K. Y.; Schech, A. J.; Mertz, P. S. Drug Synthesis and Analysis on a Dime: A Capstone Medicinal Chemistry Experience for the Undergraduate Biochemistry Laboratory. J. Chem. Educ. 2016, 93 (12), 2084 - 2088.

18. Wang, C.; Wang, X; Wang, Y.; Wang, X.; Wang, H. A Practical Procedure for the Solid-Phase Synthesis of Azo Compounds in the Undergraduate Organic Laboratory. J. Chem. Educ. 2000, 77 (7), 903-904.

19. Truran, G. A.; Aiken, K. S.; Fleming, T. R.; Webb, P. J.; Markgraf, J. H. Solid-phase Organic Synthesis and Combinatorial Chemistry: A Laboratory Preparation of Oligopeptides. J. Chem. Educ. 2002, 79 (1), 85-86.

20. Taralp, A.; Türkseven, C. H.; Cakmak, A. Ö.; Cengel, Ö. Introducing Freshmen Students to the Practice of Solid-Phase Synthesis. J. Chem. Educ. 2002, 79 (1), 87-89.

21. Kirin, S. I.; Noor, F.; Metzler-Nolte, N.; Mier, W. Manual Solid-Phase Peptide Synthesis of Metallocene-Peptide Bioconjugates. J. Chem. Educ. 2007, 84 (1), 108-111.

22. Qvit, N.; Barda, Y.; Gilon, C.; Shalev, D. E. A Laboratory Preparation of Aspartame Analogs Using Simultaneous Multiple Parallel Synthesis Methodology. J. Chem. Educ. 2007, 84 (12), 1988-1991.

23. Bockman, M. R.; Miedema, C. J.; Brennan B. B. A Discovery-Oriented Approach to Solid-Phase Peptide Synthesis. J. Chem. Educ. 2012, 89 (11), 1470 - 1473.

24. Marchetti, L.; DeBoef, B. Solution-Phase Synthesis of Dipeptides: A Capstone Project that Employs Key Techniques in an Organic Laboratory Course. J. Chem. Educ. 2015, 92 (9), 15361538.

25. Brady, S, F.; Clardy, J. Long-Chain N-Acyl Amino Acid Antibiotics Isolated from Heterologously Expressed Environmental DNA. J. Am. Chem. Soc. 2000,122 (51),12903-12904.

26. Clardy, J.; Fischbach, M. A.; Walsh, C. T. New Antibiotics from Bacterial Natural Products. Nat. Biotechnol. 2006, 24 (12), 1541-1550.

27. Walsh, C. T.; Wencewicz, T. A. Prospects for New Antibiotics: A Molecule-Centered Perspective. J. Antibiot. 201467 (1), 7-22.

28. Eibergen, N. R.; Moore, J. D.; Mattmann, M. E.; Blackwell, H. E. Potent and Selective Modulation of the RhlR Quorum Sensing Receptor by Using Non-native Ligands: An Emerging Target for Virulence Control in Pseudomonas aeruginosa. ChemBioChem. 2015, 16 (16), 2348 2356.

29. McInally, T.; Macdonald, S. J. F. Unusual Undergraduate Training in Medicinal Chemistry in Collaboration between Academia and Industry J. Med. Chem. 2017, 60 (19), 7958-7964. 
30. Vasquez, T. E.; Saldaña, C.; Muzikar, K. A.; Mashek, D.; Liu, J. M. Searching for Synthetic Antimicrobial Peptides: An Experiment for Organic Chemistry Students. J. Chem. Educ. 2016, 93 (6), 1103-1107.

31. Boltax, A. L.; Armanious, S.; Kosinski-Collins, M. S.; Pontrello, J. K. Connecting biology and organic chemistry introductory laboratory courses through a collaborative research project. Biochem. Mol. Biol. Educ. 2015, 43 (4), 233-244.

32. Opassi, G.; Gesu, A.; Massarotti, A. The Hitchiker's Guide to the Chemical-Biology Galaxy. Drug Disc. Today 2018, 23 (3), 565-574.

33. Co-ADD invites sample submission for antimicrobial screening: FREE COMPOUND SCREENING for antimicrobial activity: http://www.co-add.org/content/sending-compoundlibrary-for-high-throughput-screening (accessed May 2019)

34. Blaskovich, M. A. T.; Zuegg, J.; Elliott, A. G.; Cooper, M. A. Helping Chemists Discover New Antibiotics. ACS Infect. Dis. 2015, 1 (7), 285-287.

35. Prelab videos are available at the following links: a) Introduction to the D3 Program: https://iu.mediaspace.kaltura.com/media/Intro+D3+Lab+Lecture+9.20.18/1_8tumon9m (accessed May 2019). b) Solid-phase synthesis and the value of combinatorial chemistry, both in nature and the lab:

https://iu.mediaspace.kaltura.com/media/Combichem+and+SPS+9.21.18/1_f2c38a83 (accessed May 2019).

c) Mechanistic tutorial of the three-step D3-2 lab: deprotection, acylation and cleavage: https://iu.mediaspace.kaltura.com/media/C344F18+D32+Mech+Tutorial+Deprotect+Acylate+Cleave/1_u0a09yol (accessed May 2019) .

36. Rosenstein, I. J. A Literature Exercise Using SciFinder Scholar for the Sophomore-Level Organic Chemistry Course. J. Chem. Educ., 2005, 82 (4), 652-654.

37. Swoger, B. J. M.; Helms, E. An Organic Chemistry Exercise in Information Literacy Using SciFinder. J. Chem. Educ. 2015, 92 (4), 668-671.

38. Love, B. E.; Bennett, L. J. Determining Synthetic Routes to Consumer Product Ingredients through the Use of Electronic Resources. J. Chem. Educ. 2016, 93 (3), 567-568.

39. Initial biological data used in this exercise were generated in bioassays run at Lublin University, Poland. Protocols and complete data sets are included in Supporting Information, SI-2, pp 61-64.

40. To facilitate reaction troubleshooting in instructional laboratories and to illustrate the necessity of controls and replication in research, we strongly recommend all Bill-Boards synthesize the same known compound as a control in position A1 and that the remaining five unique compound-grid be replicated within each laboratory section. Additional detail on the utility of replication is provided in the Supporting Information, SI-2, pp 10-11. 
41. Bill-Board sets are commercially available through Chemglass: https://chemglass.com/billboard-solid-phase-syntheses-sets (accessed May 2019).

42. Due to time constraints in the instructional laboratory schedule, each student typically purifies only one sample from each Bill-Board. Additional guidelines on selecting samples for purification are provided in the SI-2, Information for Instructors, $\mathrm{p} 10$.

43. Scott, W. L.; Samaritoni, J. G.; O’Donnell, M. J.; Dounay, A. B.; Fuller, A. A.; Dave, P. S.; Sanchez, J. M.; Tiano, D. G.; Rivera, D. G. Ernest Eliel Workshop - US and Cuba Collaboration in Chemistry Education and Neglected Disease Drug Discovery. In Stereochemistry and Global Connectivity: The Legacy of Ernest L. Eliel Volume 1. 2017, 63-94.

44. These reaction products were analyzed by LC-MS at IUPUI, and results were provided to students at University of Havana.

45. Students who submitted the two failed Bill-Boards later determined that they had inadvertently omitted the diisopropylcarbodiimide during the acylation step. The absence of product in the A1 position helped students identify this systematic error.

46. Students who were unsuccessful against LO 1 were provided with a crude sample from another student Bill-Board for purification and assessment of LO 2.

47. In independent undergraduate research projects at IUPUI, quantitative ${ }^{1} \mathrm{H}$ NMR (QNMR) spectroscopy has also been used to quantify the targeted product in crude final samples (SI-2, pp 15-16), which typically contain residual water and solvent (e.g., DMF). After purification, the masses of purified products were within $20 \%$ of the QNMR calculated amounts, demonstrating the utility of this method for determining crude sample composition.

48. Hudzicki, J. The Kirby-Bauer Filter Disc Susceptibility Assay, American Society for Microbiology Microbe Library. http://www.asmscience.org/docserver/fulltext/education/protocol/protocol.3189.pdf (accessed May 2019)

49. Redelman, C. V.; Marrs, K.; Anderson, G. G. Discovering Biofilms: Inquiry-Based Activities for the Classroom. Am. Biol. Teach. 2012, 74 (5), 305-309.

50. Redelman, C. V.; Hawkins, M. A. W.; Drumwright, F. R.; Ransdell, B.; Marrs, K.; Anderson, G. G. Inquiry-based Examination of Chemical Disruption of Bacterial Biofilms. Biochem. Mol. Biol. Educ. 2012, 40 (3), 191-197.

51. Scott, W. L.; Denton, R. E.; Anderson, G.; Marrs, K.; Samaritoni, J. G.; Colglazier, S.; Lacombe, J.; Phillips, M.; O'Donnell, M. J. Identifying a Potent Inhibitor of Pseudomonas Aeruginosa through the Distributed Drug Discovery (D3) Process. Abstracts of Papers, 250th ACS National Meeting \& Exposition, Boston, MA, United States, August 16-20, 2015; American Chemical Society: Washington, DC, 2015; MEDI-52.

52. Moore, J. W. Opportunities for Collaborations Among Scholars. J. Chem. Educ. 2007, 84 (11), 1735. 
53. Koch, A. S.; Koch, H. S.; Lodder, G. An International Collaborative Undergraduate Research Program between Ithaca College and Leiden University. J. Chem. Educ. 1997, 74 (10), 11581159.

54. Alexandrova, A. N.; Huber, S. M.; Tavassoli, A. The 3rd Transatlantic Frontiers in Chemistry Symposium. Chem. Eur. J. 2013, 19 (47), 15777-15783.

55. Marmolejo-Leyva, R.; Perez-Angon, M. A.; Russell, J. M. Mobility and International Collaboration: Case of the Mexican Scientific Diaspora. PLOS One [Online] 2015, 10 (6), Article e0126720.

56. Abraham, M. M.; Denton, R. E.; Harper, R. W.; Scott, W. L.; O’Donnell, M. J.; Durrant, J. D. Documenting and Harnessing the Biological Potential of Molecules in Distributed Drug Discovery (D3) Virtual Catalogs. Chem Biol. Drug Des. 2017, 90 (5), 909-918. 